\title{
Faktor Yang Mempengaruhi Minat Pembelian Smartphone Apple Pada Mahasiswa/I Fakultas Ekonomi Universitas Tarumanagara
}

\author{
Marvin Louis dan Carunia Mulya Firdausy \\ Program Studi Manajemen Fakultas Ekonomi Universitas Tarumanagara, Jakarta \\ Email:marvinlouiss@yahoo.com
}

\begin{abstract}
The purpose of this research is to examine whether 1) perceived product quality, electronic word of mouth, and perceived price influence the purchase intention of students who use apple smartphones at the Faculty of Economics at Tarumanagara University. The population of this research is students who use apple smartphones at the Faculty of Economics at Tarumanagara University. The sample is 100 respondents with an online questionnaires with nonprobability sampling technique with purposive sampling. Overall the results of this study are 1) perceived product quality has a positive effect on purchase intention in buying Apple smartphones among students at the Faculty of Economics, Tarumanagara University. 2) electronic word of mouth has a positive effect on purchase intention in buying Apple smartphones among students at the Faculty of Economics, Tarumanagara University. 3) the perception of prices has a positive effect on purchase intention in buying Apple smartphones among students at the Faculty of Economics, Tarumanagara University. 4) perceived product quality, electronic word of mouth, and perceived price together have a positive effect on purchase intention in buying Apple smartphones among students at the Faculty of Economics, Tarumanagara University.
\end{abstract}

Keywords: Perceived Product Quality, Electronic Word of Mouth, Perceived Price, and Purchase Intention

\begin{abstract}
Abstrak: Tujuan dari penelitian ini adalah untuk menguji apakah 1) persepsi kualitas produk, elektronik dari mulut ke mulut, dan persepsi harga mempengaruhi niat pembelian siswa yang menggunakan smartphone apel di Fakultas Ekonomi di Universitas Tarumanagara. Populasi penelitian ini adalah siswa yang menggunakan ponsel cerdas apel di Fakultas Ekonomi di Universitas Tarumanagara. Sampel penelitian adalah 100 responden dengan kuesioner online dengan teknik nonprobability sampling dengan purposive sampling. Secara keseluruhan hasil penelitian ini adalah 1) persepsi kualitas produk berpengaruh positif terhadap niat beli smartphone Apple di kalangan mahasiswa di Fakultas Ekonomi, Universitas Tarumanagara. 2) elektronik dari mulut ke mulut memiliki efek positif pada niat beli dalam membeli smartphone Apple di kalangan mahasiswa di Fakultas Ekonomi, Universitas Tarumanagara. 3) persepsi harga memiliki efek positif pada niat beli dalam membeli smartphone Apple di kalangan mahasiswa di Fakultas Ekonomi, Universitas Tarumanagara. 4) persepsi kualitas produk, kata elektronik dari mulut ke mulut, dan harga yang dipersepsikan bersama-sama memiliki efek positif pada niat beli dalam membeli ponsel cerdas Apple di kalangan mahasiswa di Fakultas Ekonomi, Universitas Tarumanagara.
\end{abstract}

Kata Kunci : Kualitas Produk yang Dirasakan, Elektronik Mulut ke Mulut, Persepsi Harga, Minat Pembelian 


\section{LATAR BELAKANG}

Pada zaman yang serba digital saat ini, tidak ada yang tidak mengenal atau meggunakan smartphone. Hal ini karena selain sangat berguna, smartphone juga selalu ada untuk melengkapi hidup kita sehari-hari. Smartphone berguna untuk mendapatkan berbagai macam informasi serta memudahkan kita dalam hal-hal tertentu dan juga merupakan alat komunikasi yang sangat baik untuk berinteraksi dengan orang-orang yang berada di luar jangkauan. Adanya smartphone juga membantu kita untuk mendapatkan kabar dari orangorang terdekat kita dan smartphone juga memiliki fitur aplikasi game atau permainan yang disediakan untuk menghibur kita saat melakukan aktivitas sehari-hari agar tidak mudah jenuh.

Banyak perusahaan smartphone yang meluncurkan berbagai macam produk smartphonenya untuk memenuhi permintaan pasar. Kotler dan Keller (2009:4) menjelaskan bahwa produk merupakan segala sesuatu yang dapat ditawarkan kepada pasar untuk memuaskan suatu keinginan atau kebutuhan, termasuk barang fisik, jasa, pengalaman, acara, orang, tempat, properti, organisasi dan ide.

Terdapat beberapa merek smartphone yang bersaing di Indonesia antara lain Samsung, Apple, Huawei, Xiaomi, Oppo dan lain-lain. Pasar smartphone seperti ini menyebabkan persaingan yang ketat diantara para kompetitor usaha di bidang telekomunikasi. Kemunculan teknologi smartphone membuat berbagai vendor berlomba untuk menciptakan produk smartphone unggulan, sehingga semakin banyak pilihan dari berbagai merek dan semakin ketat pula persaingannya.Banyaknya pilihan tersebut membuat permintaan atas smartphone semakin meningkat.

Merk smartphone yang akan di bahas dalam penelitian ini adalah smartphone Apple. Siapa yang tidak mengetahui smartphone Apple, smartphone Apple adalah jajaran telepon pintar yang dirancang dan dipasarkan oleh Apple Inc. Apple Inc sendirinya adalah sebuah perusahaan multinasional yang berpusat di Silicon Valley, Cupertino, California dan bergerak dalam bidang perancangan, pengembangan, dan penjualan barangbarang yang meliputi elektronik konsumen, perangkat lunak komputer, serta komputer pribadi. Apple Inc. didirikan pada tanggal 1 April, 1976 dan di konporasikan menjadi Apple Computer, Inc. pada tanggal 3 Januari, 1977. Pada 9 Januari, 2007, kata "Computer" dihapus untuk mencerminkan fokus Apple terhadap bidang elektronik konsumen pasca peluncuran iPhone.

Smartphone Apple merupakan merek ternama yang telah di kenal oleh masyarakat Indonesia dengan kualitas produk yang telah di percaya sebagai produk yang paling di minati masyarakat baik dari segi kualitas produk, desain produk maupun harga. Namun pada saat ini iPhone tidak lagi seperti dulu dikarenakan banyaknya produk smartphone merek lainnya yang menjual smartphone dengan harga yang lebih murah dengan teknologi yang kurang lebih sama, salah satunya Indonesia lebih tertarik dengan harga iPhone model lama, dibandingkan harga iPhone model baru.

Dari data diatas maka akan dilakukan analsis beberapa faktor yang mempengaruhi minat pembelian pada mahasiswa/I fakultas ekonomi Universitas Tarumanagara yaitu kualitas produk yang dirasakan, electronic word of mout, dan persepsi harga. 


\section{KAJIAN TEORI}

\section{Kualitas produk yang dirasakan dan minat pembelian}

Menurut Aaker (1997) kualitas produk yang dirasakan persepsi konsumen terhadap keseluruhan kualitas atau keunggulan suatu produk atau jasa layanan yang sama dengan maksud yang diharapkan. Menurut Zeithaml (1988) kualitas produk yang dirasakan adalah penilaian konsumen tentang keunggulan atau superioritas produk secara keseluruhan. Hasil penelitian oleh Wells, et al. (2011), Wang (2015), dan Tsiotsou (2006) yang menyatakan terdapat pengaruh yang signifikan variabel kualitas produk yang dirasakan terhadap minat pembelian.

\section{Electronic word of mouth dan minat pembelian}

Thurau, et al. (2004) mendefinisikan electronic word of mouth adalah pernyataan positif atau negatif yang dibuat oleh konsumen potensial, konsumen riil, atau mantan konsumen tentang sebuah produk atau perusahaan yang dapat diakses oleh banyak orang atau institusi melalui internet. Kemudian menurut Westbrook (1987) electronic word of mouth adalah cara komunikasi yang memberikan informasi kepada konsumen tentang penjual dan penggunaan produk dan layanan melalui teknologi berbasis internet. Hasil penelitian oleh Jalilvand dan Samiei (2012), Abubakar, et al. (2016), dan Kudeshia dan Kumar (2017) menyatakan bahwa terdapat pengaruh yang signifikan variabel electronic word of mouth terhadap minat pembelian.

\section{Persepsi harga dan minat pembelian}

Cockril dan Goode (2010:368) mendefinisikan persepsi harga adalah faktor psikologis dari berbagai segi yang mempunyai pengaruh yang penting dalam reaksi pelanggan kepada harga. Lee dan Lawson-Body (2011) mendefinisikan persepsi harga adalah penilaian konsumen dan bentuk emosional yang terasosiasi mengenai apakah harga yang ditawarkan oleh penjual dan harga yang dibandingkan dengan pihak lain masuk diakal, dapat diterima atau dapat dijustifikasi. Hasil penelitian oleh Chiang \& Jang (2007), Wang \& Chen (2016), dan Li (2017) menyatakan bahwa terdapat pengaruh yang signifikan variabel persepsi harga terhadap minat pembelian.

\section{Minat pembelian}

Lin dan Lin (2007) mendefinisikan minat pembelian adalah proses yang digunakan untuk mengevaluasi pengambilan keputusan konsumen. Kotler (2000) mendefinisikan minat pembelian adalah perilaku konsumen yang terjadi ketika konsumen dirangsang oleh faktor eksternal dan keputusan membeli berdasarkan karakteristik pribadi mereka dan proses pengambilan keputusan.

Berdasarkan dari penjelasan setiap variabel di atas, kualitas produk yang dirasakan, electronic word of mouth, persepsi harga dan minat pembelian, dapat di simpulkan sebagai hipotesis berikut. 


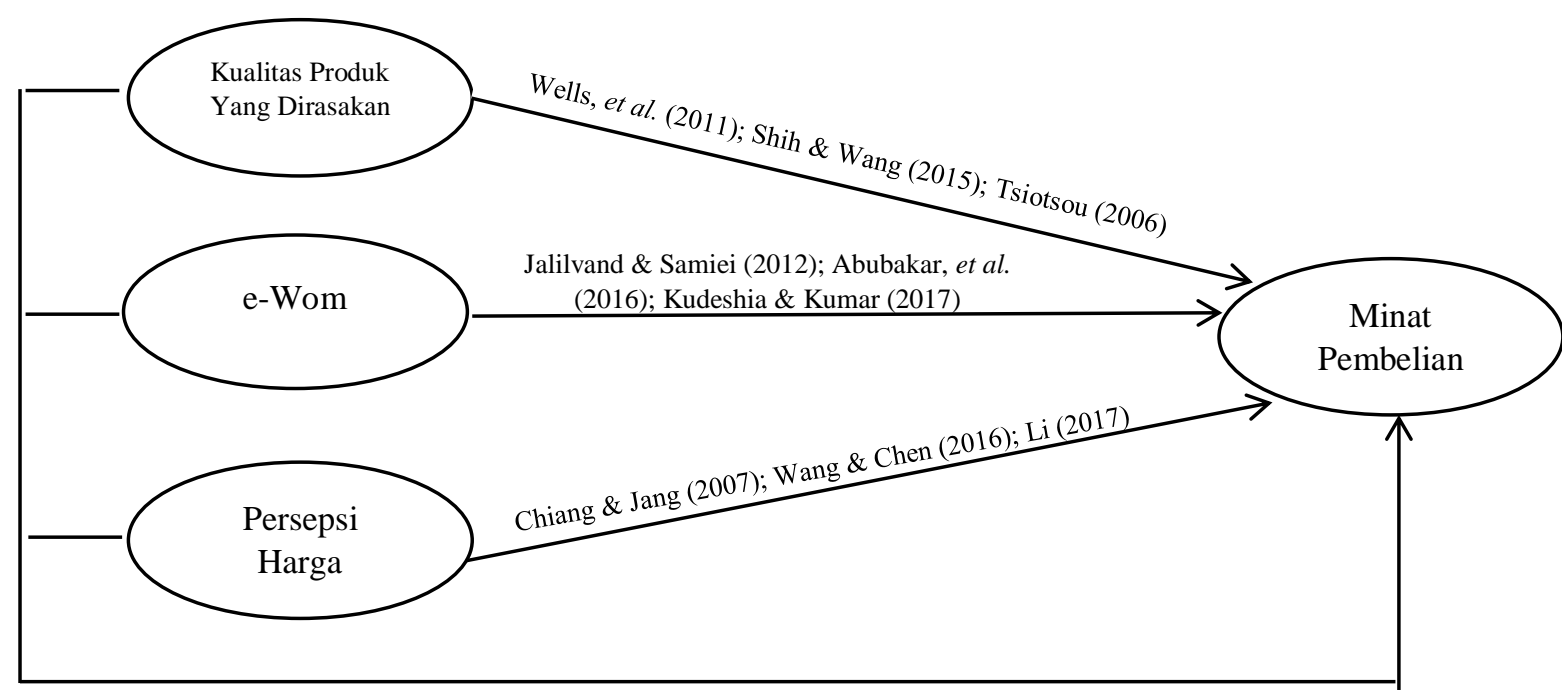

Gambar 1

Kerangka Pemikiran

Hipotesis dari model yang dibangun di atas adalah sebagai berikut :

$\mathrm{H}_{1}$ : $\quad$ Kualitas produk yang dirasakan mempunyai pengaruh yang positif terhadap minat pembelian smartphone Apple pada mahasiswa/i Fakultas Ekonomi Universitas Tarumanagara.

$\mathrm{H}_{2}$ : Electronic word of mouth mempunyai pengaruh yang positif terhadap minat pembelian smartphone Apple pada mahasiswa/i Fakultas Ekonomi Universitas Tarumanagara.

$\mathrm{H}_{3}$ : Persepsi harga mempunyai pengaruh yang positif terhadap minat pembelian smartphone Apple pada mahasiswa/i Fakultas Ekonomi Universitas Tarumanagara.

$\mathrm{H}_{4}$ : Kualitas produk yang dirasakan, electronic word of mouth, dan persepsi harga secara bersama-sama mempunyai pengaruh yang positif terhadap minat pembelian smartphone Apple pada mahasiswa/i Fakultas Ekonomi Universitas Tarumanagara.

\section{METODOLOGI}

Desain yang digunakan dalam penelitian ini adalah penelitian deskriptif dengan mengunakan pendekatan kuantitatif. Sekaran dan Bougie (2013) menyatakan bahwa penelitian deskriptif adalah penilitian yang mendeskripsikan karakteristik baik dari orang, keadaan, ataupun situasi. Berdasarkan penjelasan tersebut maka desain penelitian deskriptif digunakan untuk menguji apakah pengaruh kualitas produk yang dirasakan, electronic word of mouth, dan persepsi harga terhadap minat pembelian smartphone Apple pada mahasiswa/i Fakultas Ekonomi Universitas Tarumanagara. Nazir (2005:271) menyatakan populasi adalah kumpulan dari individu dengan kualitas serta ciri - ciri yang telah ditetapkan. Populasi yang menjadi subyek penilitan ini yaitu Mahasiswa/i Fakultas Ekonomi Universitas Tarumanagara yang menggunakan smartphone Apple.

Menurut Nazir (2005:271) sampel adalah bagian dari populasi. Dalam penelitian ini, peneliti menggunakan metode non-probability sampling (metode sampel secara tidak acak) dimana non-probability sampling adalah teknik seleksi unsur populasi untuk dijadikan sampel dilakukan atas dasar pertimbangan peneliti atau pewawancara lapangan dimana 
setiap unsur dalam populasi yang terpilih, sama sekali tidak memilki kesempatan yang diketahui (Kinnear \& Taylor, 1996 : 204). Peneliti menggunakan non-probability sampling karena non-probability sampling membutuhkan waktu, tenaga, dan biaya yang lebih kecil dibandingan probability sampling. Sedangkan teknik non-probability sampling yang digunakan adalah purposive sampling (bertujuan). Dimana purposive sampling yaitu pemilihan sample yang sesuai dengan kriteria yang telah ditentukan oleh peneliti (Silalahi, 2012:259). Peneliti membuat kuesioner dan menyebar form kepada responden yang dapat dijadikan sampel dalam penelitian ini yaitu mahasiswa/i Fakultas Ekonomi Universitas Tarumanagara dengan menggunakan google form yang di sebar kepada mahasiwa/i yang menggunakan smartphone Apple.

Menurut Sekaran \& Bougie (2013) faktor yang mempengaruhi penentuan ukuran sampel adalah tujuan penelitian, tingkat presisi yang diinginkan, tingkat resiko yang dapat diterima pada tingkat keyakinan tertentu, variabilitas populasi, keterbatasan waktu dan biaya dan ukuran dari populasi, sedangkan menurut Fraenkel dan Wallen (2007:105) ukuran sampel untuk penelitian deskriptif dengan jumlah 100 subjek penelitian, tergolong mendasar. Berdasarkan pada uraian tersebut, maka jumlah sampel yang akan digunakan oleh peneliti dalam penelitian ini adalah sebanyak 100 mahasiswa/i Fakultas Ekonomi Universitas Tarumanagara yang telah di pilih khusus yang menggunakan smartphone Apple.

\section{Hasil Uji Validitas dan Realibilitas dan Uji Asumsi Analisi Data}

Uji Outer Model. Uji model terdiri dari Uji Validitas dan Uji Reliabilitas.

Tabel 1. Hasil Uji Validitas Kualitas Produk yang Dirasakan

\begin{tabular}{|c|c|c|c|}
\hline Variabel & $\begin{array}{c}\text { Corrected Item- } \\
\text { Total Correlation }\end{array}$ & $\begin{array}{c}\text { Standar } \\
\text { Minimum }\end{array}$ & Keterangan \\
\hline $\begin{array}{c}\text { Kualitas Produk yang } \\
\text { Dirasakan 1 }\end{array}$ & 0,671 & 0,3 & Valid \\
\hline $\begin{array}{c}\text { Kualitas Produk yang } \\
\text { Dirasakan 2 }\end{array}$ & 0,705 & 0,3 & Valid \\
\hline $\begin{array}{c}\text { Kualitas Produk yang } \\
\text { Dirasakan 3 }\end{array}$ & 0,708 & 0,3 & Valid \\
\hline $\begin{array}{c}\text { Kualitas Produk yang } \\
\text { Dirasakan 4 }\end{array}$ & 0,713 & 0,3 & Valid \\
\hline
\end{tabular}

Nilai dari corrected item-total correlation untuk setiap variabel diatas menunjukan angka yang lebih besar dari 0,3 berarti setiap butir variabel memberikan hasil yang valid. 
Tabel 2. Hasil Uji Validitas Electronic Word Of Mouth

\begin{tabular}{|c|c|c|c|}
\hline Variabel & $\begin{array}{c}\text { Corrected Item- } \\
\text { Total Correlation }\end{array}$ & $\begin{array}{c}\text { Standar } \\
\text { Minimum }\end{array}$ & Keterangan \\
\hline Electronic Word Of Mouth 1 & 0,737 & 0,3 & Valid \\
\hline Electronic Word Of Mouth 2 & 0,755 & 0,3 & Valid \\
\hline Electronic Word Of Mouth 3 & 0,695 & 0,3 & Valid \\
\hline
\end{tabular}

Nilai dari corrected item-total correlation untuk setiap variabel diatas menunjukan angka yang lebih besar dari 0,3 berarti setiap butir variabel memberikan hasil yang valid.

Tabel 3. Hasil Uji Validitas Persepsi Harga

\begin{tabular}{|c|c|c|c|}
\hline Variabel & $\begin{array}{c}\text { Corrected Item-Total } \\
\text { Correlation }\end{array}$ & $\begin{array}{c}\text { Standar } \\
\text { Minimum }\end{array}$ & Keterangan \\
\hline Persepsi Harga 1 & 0,466 & 0,3 & Valid \\
\hline Persepsi Harga 2 & 0,559 & 0,3 & Valid \\
\hline Persepsi Harga 3 & 0,614 & 0,3 & Valid \\
\hline
\end{tabular}

Nilai dari corrected item-total correlation untuk setiap variabel diatas menunjukan angka yang lebih besar dari 0,3 berarti setiap butir variabel memberikan hasil yang valid.

Tabel 4. Hasil Uji Validitas Minat Pembelian

\begin{tabular}{|c|c|c|c|}
\hline Variabel & $\begin{array}{c}\text { Corrected Item-Total } \\
\text { Correlation }\end{array}$ & $\begin{array}{c}\text { Standar } \\
\text { Minimum }\end{array}$ & Keterangan \\
\hline Minat Pembelian 1 & 0,675 & 0,3 & Valid \\
\hline Minat Pembelian 2 & 0,529 & 0,3 & Valid \\
\hline Minat Pembelian 3 & 0,625 & 0,3 & Valid \\
\hline Minat Pembelian 4 & 0,658 & 0,3 & Valid \\
\hline
\end{tabular}

Nilai dari corrected item-total correlation untuk setiap variabel diatas menunjukan angka yang lebih besar dari 0,3 berarti setiap butir variabel memberikan hasil yang valid.

Tabel 5. Hasil Uji Reliabilitas Variabel

\begin{tabular}{|c|l|c|c|}
\hline No & \multicolumn{1}{|c|}{ Instrument Variabel } & $\begin{array}{c}\text { Cronbach } \\
\text { Alpha }\end{array}$ & Keterangan \\
\hline 1 & Kualitas Produk yang Dirasakan & 0,850 & Reliabel \\
\hline 2 & Electronic Word Of Mouth & 0,854 & Reliabel \\
\hline 3 & Persepsi Harga & 0,709 & Reliabel \\
\hline 4 & Minat Pembelian & 0,805 & Reliabel \\
\hline
\end{tabular}


Hasil nilai perolehan Cronbach's Alpha untuk semua variabel lebih besar dari 0,7 sehingga variabel-variabel tersebut dinyatakan reliabel.

Tabel 6. Hasil Uji Multikolinearitas

\begin{tabular}{|c|c|c|c|}
\hline \multicolumn{4}{|c|}{ Coefficients $^{\mathbf{a}}$} \\
\hline \multicolumn{2}{|r|}{ Model } & \multicolumn{2}{|c|}{ Collinearity Statistics } \\
\hline & & Tolerance & $V I F$ \\
\hline 1 & (Constant) & & \\
\hline 2 & Kualitas Produk yang Dirasakan & ,490 & 2,040 \\
\hline 3 & Electronic Word Of Mouth & ,399 & 2,505 \\
\hline 4 & Persepsi Harga & ,527 & 1,899 \\
\hline
\end{tabular}

seluruh variabel independen memiliki nilai VIF kurang dari 10, maka tidak terdapat multikolinearitas pada model regresi.

Tabel 7. Hasil Uji Heteroskedastisitas

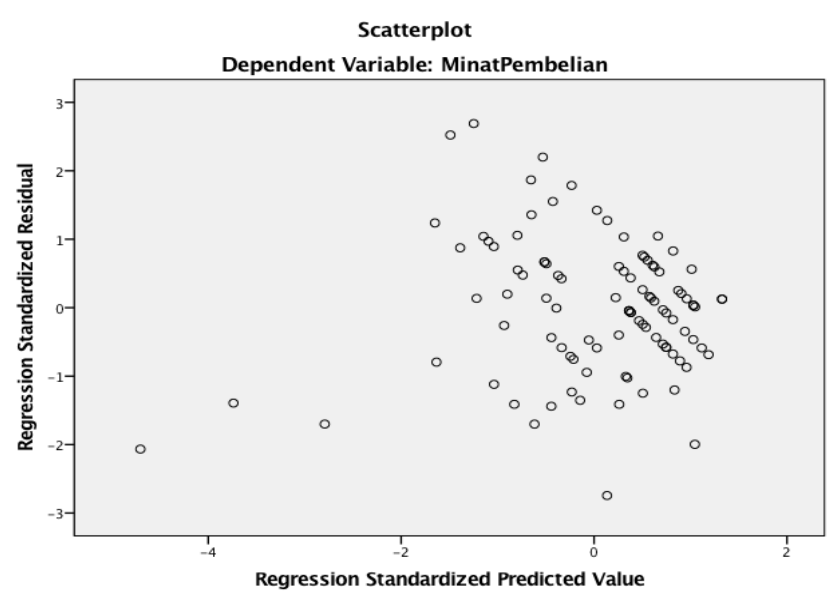

Dapat dilihat bahwa titik menyebar di atas dan di bawah angka nol dari sumbu Y, maka model memiliki kesamaan varians atau tidak terjadi heterokedastisitas.

Tabel 8. Hasil Uji Normalitas

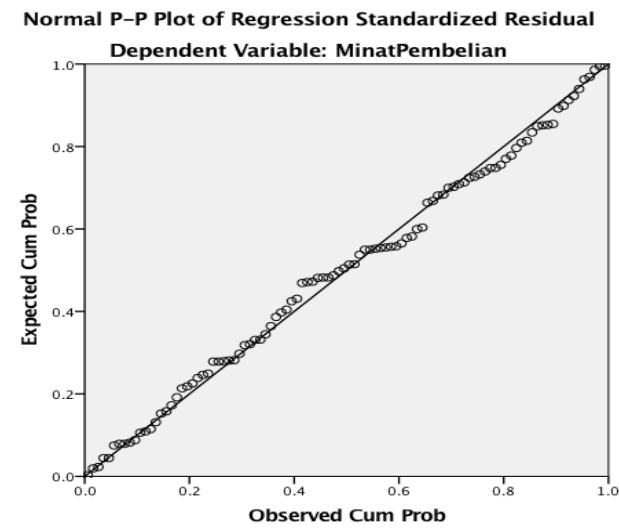


Seluruh titik-titik berada relatif dekat dengan garis sehingga dapat disimpulkan bahwa seluruh data pada model regresi terdistribusi normal. Berdasarkan hasil pengujian asumsi klasik, maka model regresi layak digunakan dalam analisis.

Tabel 9. Hasil Perhitungan Regresi

\begin{tabular}{|c|c|c|c|c|c|c|c|c|}
\hline \multirow{2}{*}{\multicolumn{2}{|c|}{ Model }} & \multicolumn{2}{|c|}{$\begin{array}{l}\text { Unstandardized } \\
\text { Coefficients }\end{array}$} & \multirow{2}{*}{$\begin{array}{c}\begin{array}{c}\text { Standardized } \\
\text { Coefficients }\end{array} \\
\text { Beta }\end{array}$} & \multirow[t]{2}{*}{$\mathbf{t}$} & \multicolumn{3}{|c|}{ Collinearity Statistics } \\
\hline & & B & $\begin{array}{c}\text { Std. } \\
\text { Error }\end{array}$ & & & \multicolumn{2}{|c|}{ Tolerance } & \multirow[t]{2}{*}{ VIF } \\
\hline 1 & $\begin{array}{l}\text { (Constant } \\
\text { ) }\end{array}$ & ,927 &, 402 & & 2,307 & 023 & & \\
\hline 2 & $\begin{array}{l}\text { Kualitas } \\
\text { Produk } \\
\text { yang } \\
\text { Dirasakan }\end{array}$ & ,389 & ,091 & ,361 & 4,275 & 000 & ,490 & $\begin{array}{c}2,04 \\
0\end{array}$ \\
\hline 3 & $\begin{array}{l}\text { Electronic } \\
\text { Word of } \\
\text { Mouth }\end{array}$ & ,144 & ,077 & , 176 & 1,879 & 063 & ,399 & $\begin{array}{c}2,50 \\
5\end{array}$ \\
\hline 4 & $\begin{array}{l}\text { Persepsi } \\
\text { Harga }\end{array}$ & ,326 & ,067 & ,396 & 4,866 &, 000 &, 527 & $\begin{array}{c}1,89 \\
9\end{array}$ \\
\hline
\end{tabular}

Berdasarkan hasil tersebut diatas, diperoleh persamaan regresi berganda sebagai berikut:

$$
\mathrm{Y}=0,927+0,389 \mathrm{X}_{1}-0,144 \mathrm{X}_{2}+0,326 \mathrm{X}_{3}
$$

Tabel 10. Tabel Uji F

\begin{tabular}{|c|c|c|c|c|c|c|}
\hline \multicolumn{7}{|c|}{ ANOVA $^{\text {a }}$} \\
\hline \multicolumn{2}{|c|}{ Model } & $\begin{array}{c}\text { Sum of } \\
\text { Squares }\end{array}$ & df & $\begin{array}{c}\text { Mean } \\
\text { Square }\end{array}$ & F & Sig. \\
\hline 1 & Regression & 47,123 & 3 & 15,708 & 63,454 & $0,000^{\mathrm{b}}$ \\
\hline 3 & Residual & 23,764 & 96 & 0,248 & & \\
\hline T. Variabel Dependen: Minat Pembelian & Total & 70,877 & 99 & & & \\
\hline
\end{tabular}

Berdasarkan hasil analisis SPSS versi 20 yang disajikan pada Tabel 4.7, output ANOVA diatas terlihat bahwa sig $<0,05$ yang berarti $\mathrm{H}_{0}$ ditolak, artinya kualitas produk yang dirasakan, electronic word of mouth, dan persepsi harga secara bersama-sama mempunyai pengaruh yang positif terhadap minat pembelian karena nilai signifikansi $0,000<0,05$. 
Tabel 11. Uji Koefisien Determinasi Ganda $\left(\mathrm{R}^{2}\right)$

\begin{tabular}{|c|c|c|c|c|}
\hline \multicolumn{5}{|c|}{ Model Summary $^{\mathbf{b}}$} \\
\hline Model & $\mathbf{R}$ & $\begin{array}{c}\text { R } \\
\text { Square }\end{array}$ & $\begin{array}{c}\text { Adjusted R } \\
\text { Square }\end{array}$ & $\begin{array}{c}\text { Std. Error of the } \\
\text { Estimate }\end{array}$ \\
\hline 1 &, $815^{\text {a }}$ &, 665 &, 654 &, 497538 \\
\hline
\end{tabular}

Besarnya koefisien determinasi berdasarkan $\mathrm{R}$ square adalah 0,665, hal ini menunjukkan bahwa sebesar $66,5 \%$ variasi minat pembelian dapat dijelaskan oleh variabel kualitas produk yang dirasakan, electronic word of mouth dan persepsi harga. Sisanya sebesar 33,5\% dapat dijelaskan oleh variabel lain.

\section{DISKUSI}

Berdasarkan Hasil uji hipotesis $1\left(\mathrm{H}_{1}\right)$ menunjukan bahwa Nilai signifikansi untuk variabel kualitas produk yang dirasakan adalah sebesar 0,000. Nilai ini lebih kecil daripada 0,05 sehingga hipotesis pertama yang menyatakan bahwa kualitas produk yang dirasakan mempunyai pengaruh yang signifikan terhadap minat pembelian dinyatakan diterima, artinya terdapat pengaruh positif dan signifikan variabel kualitas produk yang dirasakan terhadap minat pembelian. kemudian hasil uji hipotesis $2\left(\mathrm{H}_{2}\right)$ menunjukan bahwa Nilai signifikansi untuk variabel electronic word of mouth adalah sebesar 0,063. Nilai ini lebih besar daripada 0,05 sehingga hipotesis kedua yang menyatakan bahwa terdapat pengaruh yang signifikan variabel electronic word of mouth terhadap minat pembelian dinyatakan ditolak, artinya tidak terdapat pengaruh positif dan signifikan variabel electronic word of mouth terhadap minat pembelian. Terakhir hasil uji hipotesis $3\left(\mathrm{H}_{3}\right)$ menunjukan bahwa Nilai signifikansi untuk variabel persepsi harga adalah sebesar 0,00. Nilai ini lebih kecil daripada 0,05 sehingga hipotesis ketiga yang menyatakan bahwa terdapat pengaruh yang signifikan variabel persepsi harga terhadap minat pembelian dinyatakan diterima, artinya terdapat pengaruh positif dan signifikan variabel persepsi harga terhadap minat pembelian.

\section{PENUTUP}

Berdasarkan hasil pengujian data dalam penelitian ini, minat pembelian mahasiswa/i dipengaruhi oleh variabel Kualitas produk yang dirasakan, karena dengan memiliki kualitas produk makan mahasiswa/i lebih memilki ketertarikan untuk membeli, mahasiswa/i akan semakin puas jika smartphone apple memiliki kualitas yang baik. Namun electronic word of mouth tidak mempengaruhi minat pembelian, karena mahasiswa/i universitas Tarumangara lebih mementingkan sebuah brand/merek yang sudah di percayai sejak lama dan sudah merasakan sendiri kepuasan atau kualitas yang di dapatkan berdasarkan pengalaman. Berdasarkan pengujian data, minat pembelian di pengaruhi oleh variabel persepsi harga karena mahasiswa/i universitas Tarumanagara rela 
membeli smartphone apple yang memiliki harga tinggi namun memiliki kualitas yang tinggi juga.

Keterbatasan dari penelitian ini dikarenakan : peneliti menggunakan kuesioner secara online, yaitu terkadang jawaban yang diberikan responden tidak menunjukkan keadaan yang sesungguhnya.

Berdasarkan hasil dan keterbatasan di atas, maka disaran yang dapat diberikan untuk peneliti selanjutnya dapat meneliti variabel varibel yang lainnya diluar dari variabel yang telah digunakan pada penelitian ini, seperti kepuasan pelanggan, citra merek, dan kesadaran merek. Dengan menggunakan variabel variabel lainnya, maka akan memperluas hasil penelitian tidak hanya terpaku dengan kualitas pelayanan, kepercayaan, dan kualitas makanan saja. Selanjutnya peneliti menyarankan agar jumlah ukuran sampel dapat diperbanyak melebihi 100 responden. Peneliti menyarankan kepada pihak perusahaan smartphone apple agar selalu meningkatkan kualitas produk yang dirasakan lebih maksimal atau selalu mengeluarkan inovasi-inovasi terbaru pada smartphone Apple agar konsumen tetap mempunyai minat untuk membeli produk smartphone Apple di bandingkan merek lain.

\section{DAFTAR PUSTAKA}

Aaker, David A., 1997, Manajemen Ekuitas Merek: Memanfaatkan Nilai dari Suatu Merek. Jakarta: Mitra Utama.

Abubakar, A. M., Ilkan, M., \& Sahin, P. (2016).eWOM, eReferral and gender in the virtual community. Marketing Intelligence \& Planning, 34(5), 692-710.

Cockrill, Antje., Mark M.H. Goode. 2010. Perceived Price And Price Decay In the DVD Market. The Journal of Product And Brand Management.

Chiang, C.-F., \& Jang, S. S. (2007). The Effects of Perceived Price and Brand Image on Value and Purchase Intention: Leisure Travelers'Attitudes Toward Online Hotel Booking. Journal of Hospitality \& Leisure Marketing, 15(3), 49-69

D.V. Parboteeah, J. S. Valacich, and J. D. Wells, The influence of website characteristics on a consumer's urge to buy impulsively. Information Systems Research, vol. 20, no. 1, pp. 60-78, 2009.

Ferdinand, Augusty. 2002. Structural Equation Modelling dalam Penelitian Manajemen. Semarang:FE UNDIP.

Grewal, Dhruv, Kent B. Monroe, and R. Krishnan. 1998. "The Effects of Price Comparisons Advertising on Buyers' Perceptions of Acquisition Value, Transaction Value, and Behavioral Intentions." Journal of Marketing 62 (2): 4659.

Gruen,T. W., Osmonbekov, T., Czaplewski, A. J(2006). e-WOM: the impact of customer to customer online know-how exchange on customer value and loyalty. Journal of Business Research, 59(4), 449-456.

J. Paul Peter dan Jerry C. Olson. 2002. Consumer Behavior:Perilaku Konsumen dan Strategi Pemasaran. Jakarta : Erlangga

Kotler, Philip dan Kevin Lane Keller. 2009. Alih Bahasa :Benyamin Molan. Manajemen Pemasaran. Edisi Ketigabelas. Jilid 1 dan 2. Cetakan Keempat. PT. Indeks. Jakarta. 
Kinnear, Thomas C dan James R Taylor., 1996., "Marketing research: An Applied Approach., 5th edition., USA

Kudeshia, C., \& Kumar, A. (2017).Social eWOM: does it affect the brand attitude and urchase intention of brands? Management Research Review, 40(3), 310330.

Lee, Simon; Abdou Illia., Lawson-Body, Assion. 2011. Perceived Price Of Dynamic Pricing.Journal of Industrial Management \& Data System, 111

Li, Cheng-Ping, C. (2017).Effects of Brand Image, Perceived Price, Perceived Quality, and Perceived Value on the Purchase Intention towards Sports and Tourism Products of the 2016 Taichung International Travel Fair. The Journal of International Management Studies, 12(2), 104.

Lin, Nan Hong \& Lin, Bih Shya, (2007). "The Effect of Brand Image and Product Knowledge on Purchase Intention Moderated by Price Discount". Journal of International Management Studies.

Nazir M. 2005. Metode Penelitian. Jakarta: Ghalia Indonesia. Hal 271.

Sekaran, Uma dan Bougie, Roger. 2013. Research Methods for Business. United Kingdom: Jhon Wiley \& Sons Ltd.

Silalahi, U. (2012). MetodePenelitianSosial. Bandung: RefikaAditama. Hal 259. , Ulber.2012. Metode Penelitian Sosial. Bandung: Refika Aditama. Hal 237-238.

Tsiotsou, R. (2006). The role of perceived product quality and overall satisfactionon purchase intentions. International Journal of Consumer Studies, 30(2), 207-217.

Westbrook, (1987).Product/ Consumption Based Affective Responses and Post Purchase Processes. Journal of Marketing Research. 24-(3) 258-270.

Wang, E. S.-T. (2015). Different Effects of Utilitarian and Hedonic Benefits of Retail Food Packaging on Perceived Product Quality and Purchase Intention.Journal of Food Products Marketing, 23(3), 239-250.

Wang, Ya-Hui \& Li-Yan Chen. (2016). An Empirical Study of The Effect of Perceived Price on Purchase Intention Evidence from Low-Cost Carriers.International Journal of Business and Social Science Vol.7 No.4.

Wells, Valacich, \& Hess. (2011). What Signal Are You Sending? How Website Qualit Influences Perceptions of Product Quality and Purchase Intentions. MI Quarterly, 35(2), 373.

Zeithaml, Valarie A. 1988. Consumer Perceptions Of Price, Quality, And Value : A Means-End Model And Systhesis Of Evidence. Journal Of Marketing, Vol.52, pp. 2 22. 